\title{
Raman Scattering Measurements of Mixing and Finite-Rate Chemistry in a Supersonic Reacting Flow over a Piloted, Ramped Cavity
}

\author{
Nathan R. Grady', Robert W. Pitz, Campbell D. Carter ${ }^{2}$, and Kuang-Yu Hsu ${ }^{3}$ \\ ${ }^{1}$ Mechanical Engineering Department, Vanderbilt University, Nashville, TN 37235 \\ ${ }^{2}$ U.S. Air Force Research Laboratory, Wright-Patterson Air Force Base, Ohio 45433 \\ ${ }^{3}$ Innovative Scientific Solutions, Inc., Dayton, Ohio 45440
}

\begin{abstract}
UV Raman scattering is applied to measure fuel/air mixing and combustion of a Mach-2 air stream flowing over a step-ramp cavity fueled with $70 \%$ methane $/ 30 \%$ hydrogen. Average and RMS fluctuations of temperature and major species profiles as well as scatter plots of simultaneous temperature and chemical scalars are determined from single-shot Raman scattering measurements along a 6-mm line transverse to the main supersonic flow. In the fuel-rich regions of the pilot cavity, the 248-nm KrF laser induces broadband fluorescence interference that reduces the number of analyzable Raman spectra; nonetheless, on the whole, a significant fraction of the spectra were reducible. In the cavity, hydrogen fuel reacts quickly resulting in a uniform water concentration in the recirculation zone. Methane reacts slowly to carbon monoxide/carbon dioxide in the cavity, leading to non-uniform concentrations of these species. Mean and instantaneous mixture fraction data inside the shear layer were indicative of oxygen transport across the shear layer. Temperature, water, and oxygen fluctuations are fairly constant throughout the combustor due to recirculation/turbulent transport across the shear layer and the slow reaction of methane.
\end{abstract}

Keywords: Raman, Scramjet, cavity, piloted, supersonic, diffusion, combustion

\section{Introduction}

The current Reynolds-Averaged Navier-Stokes (RANS) simulation codes used to design scramjet combustors use simplified physical models in order to calculate the complex geometry with detailed chemistry and unsteady compressible turbulent flow. While these models generally provide guidelines for future experimental efforts, they fail to capture the phenomenological flow patterns. Therefore, the use of large-eddy-simulation (LES), which promises to give improved prediction of turbulent combustion [1,2] in supersonic flows [3], has been proposed. LES is more computationally efficient than direct numerical simulation (DNS), because in LES only the large-scale features that contain the bulk of the kinetic energy are computed. LES requires subgrid closure methods to model events that occur below the grid resolution for momentum, energy, and scalar transport. Previous comparisons of numerical and experimental data by Grady et al. [4] have demonstrated the accuracy of LES to predict the flow patterns over a ramp close-out cavity under nonreacting conditions, validating subgrid closure methods for both momentum and energy transport. However, in order to validate and/or improve scalar transport closures, which model chemistry and its interaction with turbulence such as those detailed in a review paper by Gicquel et al. [5] (e.g. probability density function, flamelet, lineareddy mixing, neural networks, etc.), reacting flow data are needed. Of particular interest, is the ability of reduced chemical mechanisms to accurately predict the behavior of multi-component fuels (e.g. cracked jet fuel that have components with a wide range of reactivity) in complex geometries and flows. However, modeling jet fuel even with a reduced mechanism is computationally expensive and may have a large uncertainty. As an alternative to modeling jet fuel, a surrogate fuel with simpler chemistry can be used to facilitate simulations and still capture turbulence-chemistry interactions; however, experimental data is needed for these conditions. 
In order to verify the ability of these numerical models to predict turbulence-chemistry interaction or access the validity of reduced chemical kinetics, in situ and temporally resolved experimental measurements of temperature and species are needed in compressible flows with realistic combustors. O'Byrne et al. [6] have performed extensive coherent anti-Stokes Raman scattering (CARS) measurements of temperature and $\mathrm{O}_{2}, \mathrm{~N}_{2}$, and $\mathrm{H}_{2}$ mole fractions in a model scramjet combustor fueled with $\mathrm{H}_{2}$. [7-9]. Additionally, Fulton et al. [10] compared LES/RANS simulations to CARS measurements of temperature, and $\mathrm{O}_{2}, \mathrm{~N}_{2}$, and $\mathrm{H}_{2}$ concentrations in supersonic combustion behind a step. Of course, in a hydrocarbon-fueled combustor, measurement of all the major species is a challenge for CARS (although new developments have been demonstrated $[11,12]$ ). Spontaneous Raman scattering can satisfy this requirement (to measure all major species) using only a single laser. A detailed description of Raman scattering is given by Barlow et al. [13]. Previously, Raman scattering has been used in enclosed subsonic combustors by Meier and colleagues [14-16], in open supersonic jets by Cheng et al. [17], and in supersonic combustors without reaction by Carter and colleagues [18, 19]. However, to the authors' knowledge, Raman scattering has not been used in a supersonic, reacting wind-tunnel. In this application UV vibrational Raman scattering, based on a $\mathrm{KrF}$ excimer laser with 248-nm excitation, is employed instead of visible Raman scattering for the following reasons: 1) scattering cross sections in the UV are significantly larger than those in the visible, and therefore single-shot scattering signals are relatively large (for the same laser pulse energy); and 2) the $\sim 20$-ns $\mathrm{KrF}$ laser pulse does not require pulse stretching to avoid dielectric breakdown.

Of course, flows within a supersonic combustion ramjet or scramjet have low residence times. Wall cavity flameholders are perhaps the simplest means of providing 1) adequate residence time, 2) reliable flameholding across a wide range of flight conditions, and 3) modest drag penalty [20]. Furthermore, wall cavities within two-dimensional flowpaths can be designed to include unobstructed optical access and offer a canonical flow that can easily be modeled [4]. Previous experiments by Gruber et al. [21] and Rasmussen et al. [22] have shown that direct fueling from the rear of the cavity supports combustion over a wider range of conditions and a more uniform fuel-air mixture with longer residence times than fueling from either passive entrainment or the floor of a cavity. Furthermore, there is a large database of experimental results with this configuration [21-25], so this fueling strategy was implemented in this study.

UV spontaneous Raman scattering measurements over a ramp-closeout wall cavity flameholder fueled from the ramp will be presented in this paper. Mean, root-mean square, RMS, fluctuation, and scatter plots of temperature, species concentration, and mixture fraction will be discussed. In addition, analysis of local fuel consumption and product formation will be provided.

\section{Experimental System}

The experiments were conducted at the supersonic flow facility in Research Cell 19 at the Aerospace Systems Directorate, Wright-Patterson Air Force Base. The wind-tunnel employed a 2-D Mach-2 nozzle with an air flow rate of $3.1 \mathrm{~kg} / \mathrm{s}$. A schematic of the wind-tunnel and test section can be found in Figure 1. The coordinates given in this paper are in reference to $x=0$ being on the step in the axial direction, $\mathrm{z}=0$ being on the step in the vertical direction, and $\mathrm{y}=0$ being centered on the spanwise centerline. An isolator of constant cross section (51-mm high by $153-\mathrm{mm}$ wide) was upstream of the test section. There was a $2.5^{\circ}$ expansion of the test section floor. Flame holding was provided by a cavity, which was $16.5-\mathrm{mm}$ deep for $46-\mathrm{mm}$ before 
ascending back to the test section floor at a $22.5^{\circ}$ angle. Fused-silica windows (Esco S1-UV), located on the sides and top of the test section, allowed optical access.

The tunnel supplied heated (via a natural-gas-fueled heat exchanger), compressed air $\left(\mathrm{T}_{0}=\right.$ $\left.590 \mathrm{~K}, \mathrm{P}_{0}=415 \mathrm{kPa}\right)$ continuously that was expanded to Mach-2 conditions at the isolator $(\mathrm{T}=$ $330 \mathrm{~K}, \mathrm{P}=53 \mathrm{kPa}$ ) and was further expanded due to the $2.5^{\circ}$ divergence of the test-section floor $(\mathrm{T}=300 \mathrm{~K}, \mathrm{P}=39 \mathrm{kPa})$. It should be noted that these wind-tunnel conditions relate, roughly, to a Mach-4 scramjet flight condition; however, the resulting static temperature in the cavity region, $\sim 300 \mathrm{~K}$, is much lower than at flight conditions. Facility limitations (seals, etc.) prevented use of higher, more realistic temperatures. Furthermore, the tunnel components (made of carbon steel) are not water cooled, and therefore run times, typically 30 seconds, were limited by the heating of the cavity (particularly the ramp). The fuel used for this study was composed of $70 \%$ methane $\left(\mathrm{CH}_{4}\right)$ and $30 \%$ hydrogen $\left(\mathrm{H}_{2}\right)$, by volume, and was premixed by the manufacturer; it was intended to represent the reactivity of a vaporized hydrocarbon jet fuel but also to minimize fluorescence interference (a primary concern with the Raman scattering technique). We note too that $\mathrm{CH}_{4}$ and $\mathrm{H}_{2}$ are two components expected in a cracked jet fuel; other expected gaseous components include ethane $\left(\mathrm{C}_{2} \mathrm{H}_{6}\right)$ and ethylene $\left(\mathrm{C}_{2} \mathrm{H}_{4}\right)$. The fuel was injected parallel to the cavity floor from the cavity close-out ramp, from the locations shown in Figure 2, at a rate of 102 standard liters per minute (referenced to $273 \mathrm{~K}$ and 1 standard atmosphere), which is equivalent to a mass flow rate of $0.90 \mathrm{~g} / \mathrm{s}$. The fuel was passed through a manifold and split between the 11 fuel injectors, as shown in Figure 2. The exit velocity of the fuel can be estimated using continuity and assuming that the density of the fuel at the jet exit can be approximated using the cavity static pressure and the room temperature:

$$
V_{\text {exit }}=\frac{\dot{m} / 11}{\rho_{\text {exit }} * A_{\text {exit }}} \approx \frac{\dot{m} / 11}{\left(\frac{P_{\text {cavity }}}{R_{\text {mix }} * T_{\text {room }}}\right) A_{\text {exit }}}
$$

where the room temperature $(293 \mathrm{~K})$, injector exit area $\left(3.08 \mathrm{~mm}^{2}\right), \mathrm{R}_{\text {mix }}(702.7 \mathrm{~J} / \mathrm{kg} * \mathrm{~K})$, and the cavity static pressure $(\sim 37 \mathrm{kPa})$, resulting in a velocity of $\sim 150 \mathrm{~m} / \mathrm{s}\left(\mathrm{M}_{\text {fuel }}<0.3\right)$.

A narrowband Lambda Physik Compex $150 \mathrm{KrF}$ excimer laser $(350 \mathrm{~mJ} / \mathrm{pulse}, 20$-ns pulse length) produced 248-nm radiation that was used to excite the vibrational Raman transitions. The laser was tuned away from $\mathrm{O}_{2}$ and $\mathrm{OH}$ laser-induced fluorescence (LIF) transitions to reduce interference with the Raman lines. In order to prevent damage to the fused-silica wind-tunnel windows, following the procedure used by Wehr et al. [26], two 200-mm focal length, cylindrical lenses, oriented $90^{\circ}$ from each other, were used to focus the 248 -nm beam. Additionally, a thin-film polarizer was placed before the lenses to reject any unpolarized laser radiation. The laser-beam energy measured after the lenses was $\sim 200 \mathrm{~mJ} / \mathrm{pulse}$. Using burn patterns, the probe size was estimated to be $0.75 \mathrm{~mm}$ in the $\mathrm{x}$-direction and $1.5 \mathrm{~mm}$ in the z-direction (see Fig. 1 for the coordinate system). Raman scattering was collected through the top wind-tunnel window, collimated, and then focused onto the entrance slit of a Horiba iHR320 spectrometer using two 5-cm-diameter f/4 UV achromats, as shown in Figure 3; a 6-mm-long region of the beam was imaged, but only a 5.25 -mm-long segment was used for data processing. An n-butyl acetate liquid filter was placed before the entrance slit to block scattering at $248 \mathrm{~nm}$. Raman signals were recorded with a PIMAX Superblue ICCD (1024 x 256 pixels, full frame, with a $25-\mathrm{mm}$ intensifier) camera at a $10-\mathrm{Hz}$ frequency, matching the pulse-repetition rate of the excimer laser. The photocathode was gated at $200 \mathrm{~ns}$, and to further reduce background noise, multichannel plate gating was also used. The optics directing the $248-\mathrm{nm}$ beam to the test 
section were arranged such that the probe region could be translated vertically and axially via a remote-controlled breadboard translation table.

Bottom-wall pressures along the combustor centerline are shown in Figure 4; the pressures measured upstream of the cavity are near the predicted isentropic value of $39 \mathrm{kPa}$. The drop in pressure at the fourth data point, $\mathrm{x}=120.4 \mathrm{~mm}$ is indicative of flow separation after the ramp (c.f. Figure 5b [20]). Pressure measurements on the cavity floor $(x=0-40 \mathrm{~mm})$ varied $<1 \%$ during each dataset, so pressure was assumed to be constant during each dataset. Therefore, the ideal-gas law was invoked to determine the temperature using the calculated number densities of the major species and the pressure at $\mathrm{x}$ determined via linear interpolation of the cavity wall pressure measurements (i.e. the second and third probe locations at $\mathrm{x}=1.2 \mathrm{~cm}$ and $3.8 \mathrm{~cm}$, respectively, as shown in Figure 4). Since the number densities are in turn a function of temperature, the temperature was determined via an iterative scheme until convergence of $\pm 10 \mathrm{~K}$ was met. The RMS temperature fluctuation values were $9 \%$ in the freestream, where the true variation is expected to be very small, and $32 \%$ in the cavity, where large variations might be expected (though signals are lower, due to the reduction in total number density, and thus instrument precision will be poorer too). The Raman system was calibrated using $\mathrm{H}_{2}$-air and 70\% $\mathrm{CH}_{4} / 30 \% \mathrm{H}_{2}$-air flames stabilized on a 25 -mm-square Hencken burner (Technologies for Research Model RT1x1) at ambient pressures, and the resulting temperatures and species mole fractions are shown in Figures 5 and 6. Each calibration point is for 200 laser shots, where the values of mean and standard deviation are shown. The calibration factors for each species are shown in Figure 7 with the exception of $\mathrm{CH}_{4}$ which had a constant value of $5.28 \times 10^{20} \mathrm{\#} / \mathrm{m}^{3}$ taken at room temperature. Sample calibration spectra are also shown in Figure 8. The magnitude of cross talk between species and from $\mathrm{OH}$ or $\mathrm{O}_{2}$ fluorescent interferences was determined during the calibration procedure. $\mathrm{OH}$ LIF was subtracted from $\mathrm{H}_{2} \mathrm{O}$ and $\mathrm{CH}_{4}$ Raman signals, while $\mathrm{O}_{2}$ LIF was subtracted from $\mathrm{H}_{2}, \mathrm{CH}_{4}, \mathrm{O}_{2}$, and $\mathrm{CO}_{2}$ Raman signals. Rotational Raman scattering from $\mathrm{H}_{2}$ was subtracted from the $\mathrm{CO}_{2}, \mathrm{O}_{2}$, and $\mathrm{CO}$ lines, and a tertiary vibrational mode of $\mathrm{CH}_{4}$ is also subtracted from $\mathrm{O}_{2}$. Finally, cross talk between $\mathrm{O}_{2} / \mathrm{CO}_{2}$ and $\mathrm{CO} / \mathrm{N}_{2}$ signals as a function of temperature was determined from the calibration data. A more detailed description of this procedure is given elsewhere [27-29]. As a result of the various experimental constraints .such as having to focus close to a window, absolute accuracy of these measurements is lower than typically found in open flow configurations; however, these results still adequately capture changes in species concentration and temperature.

Since the Raman scattering measurements provide all major species and temperature, these scalar values can be plotted against mixture fraction to deduce chemistry-turbulence interaction. Mixture fraction, $\xi$, is a conserved scalar that is not affected by either the rate of the reaction or its progress and is only indicative of the mixing between the fuel and air streams. By normal definition, $\xi$ is 0 in the air stream and 1 in the fuel stream. The following definition of mixture fraction, modified by Pitsch and Peters [30] based only on the presence of $\mathrm{C}$ and $\mathrm{H}$ atoms, is used:

$$
\xi=\frac{Y_{C}+\frac{v_{H}}{v_{C}} Y_{H}}{Y_{C, 1}+\frac{v_{H}}{v_{C}} Y_{H, 1}}
$$

where $v_{j}$ are the stoichiometric elemental coefficients (for this fuel mixture: $v_{C}=7, v_{H}=34$ ), $Y_{j}$ are elemental mass fractions, and the subscript 1 represents the fuel stream. The stoichiometric 
mixture fraction for this fuel (with volumetric composition of $X_{\mathrm{CH} 4}=0.7$ and $X_{\mathrm{H} 2}=0.3$ ) is 0.0525 .

\section{Experimental Results}

Typically, the cavity was lit (using two spark igniters located on the cavity floor) with a specific fuel flow rate (for repeatable ignition); the fuel flow rate was then changed to the desired setting, and the spectra were collected; afterwards, the fuel was shut off, and the cavity was allowed to cool (before making measurements at the next location). While no videos or photographs were taken for the current experiment, the cavity flame looked qualitatively similar to previous $\mathrm{C}_{2} \mathrm{H}_{4}$ fueled flames [31]. At 8 vertical locations (9 locations at $\left.\mathrm{x}=3.5 \mathrm{~cm}\right), 200$ images were collected (from 200 laser shots), starting above the cavity shear layer and ending at the lowest point in the cavity accessible before the beam was clipped by the tunnel side-wall window frame. After a single vertical sweep was completed, the probe region was then moved axially from the upstream edge to the downstream edge of the cavity. The data taken along each Raman line were then divided into 7 line segments, each representing sample volumes of $0.75 \times$ $0.75 \times 1.5 \mathrm{~mm}^{3}$. Upstream regions of the cavity suffered from considerable LIF interference, as shown in Figure 9 alongside an example with minimal interference, and as a result some fraction of the images could not be reliably reduced (converted to concentration). Therefore, to increase the available sample size at each probe location, the data from all 7 line segments were individually reduced and then bundled together to calculate mean scalar values. The resultant number of "reducible images" from this bundling is shown in Figure 10. Experimental data of mean and RMS fluctuations are shown in Figures 11-19. As can be seen from the data in Figures $11-13$, at $\mathrm{x}=0.9 \mathrm{~cm}$ there is a high concentration of $\mathrm{CH}_{4}\left(X_{\mathrm{CH} 4}\right)$ with little $\mathrm{CO}_{2}$ at high temperatures, caused by the relatively fast reaction of $\mathrm{H}_{2}$. Furthermore, recirculation near the step in the X-Z plane (see counter-rotating vortex shown in Figure 2) can effectively trap unreacted fuel, increasing residence time and creating fuel rich pockets. Therefore, it is suggested that this LIF interference is from soot precursors [e.g., polycyclic aromatic hydrocarbons (PAH)] formed from this rich region, since such a broadband LIF interference has been observed previously from PAH and soot precursors (see Figure 14.6 in ref. [13]); nonetheless, it is noted that no test was performed to confirm PAH fluorescence as being the source of interference and no soot emission has been observed in the cavity (even with ethylene fuel, regardless of fuel flow rate). The mixture fraction data in Figure 19 show rich mixtures $(\xi>$ 0.05) along the floor and behind the step of the cavity, further corroborating the PAH fluorescence interference hypothesis. In addition, the mixture fraction steadily decreases along the shear layer, due to turbulent transport of $\mathrm{O}_{2}$ into the cavity. By $\mathrm{x}=6 \mathrm{~cm}$ on the ramp, the mixture is lean $(\xi<0.05)$ with little fuel and fluorescence interference, and almost all of spectra are reducible.

Interpretation of the RMS fluctuation data is complicated by the convolution of chemical reactions and recirculation; therefore, scatter plots will be discussed first. For the sake of analysis, the cavity combustor is divided into four regions to show the extent of mixing/chemistry throughout the combustor with two more locations, in the freestream (Location 1) and in the shear layer (Location 2) shown in Figure 20. To reduce data biasing due to the fluorescence interference, points were chosen such that at least $90 \%$ of the images were reducible. The primary recirculation pattern of the cavity is also shown in Figure 20 and 
illustrates how the fuel jet (shown as the red arrow) would first pass through Locations A through D in order before either recirculating or exiting the cavity (at the ramp). Hot products can also leave the cavity via turbulent transport through the shear layer (e.g. Location 2). Scatter plots for Locations 1, 2, and A through D are shown in Figures 21-26 with lines drawn for the appropriate adiabatic equilibrium- and mixing-without-reaction scalar values. Values greater than the equilibrium lines can be caused by measurement error, due to low signal levels, or to recirculation of hot gases.

Location 1, which is in the freestream where there should be negligible fluctuations, is included to demonstrate the uncertainty of the measurement. Other than a few instances $\left(\right.$ of $\mathrm{CO}_{2}$ detection due to cross-talk with $\mathrm{O}_{2}$ ), only $\mathrm{O}_{2}$ and $\mathrm{N}_{2}$ are observed, as expected. As a result of the low signal levels, the mean $X_{\mathrm{O} 2}$ is under-predicated by $\sim 2 \%$ (i.e., $X_{\mathrm{O} 2}=0.19$ vs. 0.21 ) and both $X_{\mathrm{N} 2}$ and $X_{\mathrm{O} 2}$ RMS fluctuations are $\sim 1.3 \%$. Location 2 shown in Figure 22 is included to demonstrate turbulent transport across the shear layer. Mean $X_{\mathrm{O} 2}$ values are roughly half that found in the main air flow over the cavity but are higher than the $X_{\mathrm{O} 2}$ inside the cavity, while RMS fluctuations are almost twice as large in the shear layer as in the main air flow.

Temperature mean and RMS fluctuation values at Location 2 are also elevated relative to the main flow but are lower than in the cavity. Trace amounts of $\mathrm{CH}_{4}$, and products are also seen in the shear layer as opposed to the main flow.

At Location A (see Figure 23), the scatter plots demonstrate that this region has intermittent partially reacted and unreacted mixtures. The $\mathrm{CH}_{4}$ data is almost entirely along the mixingwithout-reaction line, indicating that most of the $\mathrm{CH}_{4}$ has not reacted at this point in the cavity, although it has started to mix, as indicated by the points below $\xi=0.5$. Temperatures and $X_{\mathrm{H} 2 \mathrm{O}}$ vary from near adiabatic to unreacted values for $\xi<0.15$, whereas for $\xi>0.15$ there are superequilibrium temperatures and $X_{\mathrm{H} 2 \mathrm{O}}$ values. $\mathrm{CO}$ and $\mathrm{CO}_{2}$ values are between the mixing-withoutreaction and equilibrium lines for lean conditions, but with super-equilibrium $\mathrm{CO}_{2}$ values between $0.05<\xi<0.1$. Since little $\mathrm{CH}_{4}$ has reacted at Location A, the high temperatures and $X_{\mathrm{H} 2 \mathrm{O}}$ must be from either $\mathrm{H}_{2}$ combustion or from recirculation, and the presence of $\mathrm{CO}$ and $\mathrm{CO}_{2}$ must primarily be due to recirculated products.

At Location B (see Figure 24), $\mathrm{CH}_{4}$ is still largely unreacted, although more air has been entrained into the fuel jet than at Location $\mathrm{A}$. $\mathrm{CH}_{4}$ is most likely still present here in spite of the high temperatures and available oxygen, due to a $\sim 270 \mu$ s residence time (estimated based the $\sim 4$ $\mathrm{cm}$ distance between Location $\mathrm{B}$ and the fuel injection location and using the jet exit velocity of $150 \mathrm{~m} / \mathrm{s}$ ). Both the $X_{\mathrm{O} 2}$ and the $X_{\mathrm{CO}}$ profiles indicate partially reacted mixtures, while there is little $\mathrm{CO}_{2}$ observed in this region since $\mathrm{CO}$ oxidation is significantly slower than the competing $\mathrm{CH}_{4}$ breakup. Super-equilibrium values for temperature are probably due to interference and measurement error. Since there are comparable $X_{\mathrm{CO}}$ values at Locations A and $\mathrm{B}$, it is unlikely that the disappearance of $\mathrm{CO}_{2}$ at Location $\mathrm{B}$ is caused by dissociation.

At Location $\mathrm{C}$ (see Figure 25), while some of the $\mathrm{CH}_{4}$ has yet to react, the mixture is predominantly lean and reacted or at least partially reacted. When the flow moves to Location $\mathrm{D}$ (see Figure 26), the $\mathrm{O}_{2}$ and $\mathrm{CO}$ data primarily follow the adiabatic equilibrium lines while temperature and $X_{\mathrm{CO} 2}$ profiles still show partial reaction. The scatter in the $\mathrm{CO}_{2}$ data indicates that $\mathrm{CO}$ oxidation occurs between Locations $\mathrm{C}$ and $\mathrm{D}$, which is further corroborated by the $\mathrm{CH}_{4}$ data approaching the adiabatic equilibrium line between these points. The $X_{\mathrm{H} 2}$ scatter plots, included for Locations $\mathrm{C}$ and $\mathrm{D}$, indicate partial reaction of $\mathrm{H}_{2}$, which was not found at the other locations. The presence of $\mathrm{H}_{2}$ near the shear layer at Locations $\mathrm{C}$ and $\mathrm{D}$ can be explained by the water shift reaction: 


$$
\mathrm{CO}_{2}+\mathrm{H}_{2} \leftrightarrow \mathrm{H}_{2} \mathrm{O}+\mathrm{CO}
$$

The excess $\mathrm{H}_{2}$ above $30 \%$ in the equilibrium curves (see Figures 25 and 26) are also due to this water shift reaction.

Returning to Figures 11-19, fluctuations in $\xi$ and $X_{\mathrm{CH} 4}$ peak near the injection location, due to intense fuel/air mixing, while fluctuations near the step (before $\mathrm{CH}_{4}$ starts to react) are less. The profiles for CO RMS fluctuations and concentrations are similar, and in general there is less $\mathrm{CO}$ when $X_{\mathrm{CH} 4}$ is high, as expected, due to $\mathrm{CO}$ oxidation kinetics. $X_{\mathrm{CO} 2}$ fluctuations peak in regions of $\mathrm{CO}$ oxidation, primarily near the shear layer or in regions of recirculation near the ramp, while fluctuations lower in the cavity are most likely due to recirculation.

The RMS profiles for temperature, $X_{\mathrm{H} 2 \mathrm{O}}$, and $X_{\mathrm{O} 2}$ are flatter than profiles of other scalars. Inspection of the scatter plots would indicate that the initial $X_{\mathrm{O} 2}$ fluctuations are due to fuel/air mixing or the consumption of $\mathrm{O}_{2}$ in the chain-branching reaction steps, while the fluctuations further away from the injectors are due to slowly reacting $\mathrm{CH}_{4}$ or turbulent transport of $\mathrm{O}_{2}$ across the shear layer. Inspection of Location A data demonstrated that fluctuations in both $X_{\mathrm{H} 2 \mathrm{O}}$ and temperature were due to either the reaction of injected $\mathrm{H}_{2}$ or to recirculation. Additionally, the scatter plots showed that $\mathrm{H}_{2} \mathrm{O}$ was not fully at equilibrium at Location D over the ramp (although comparisons between Locations $\mathrm{C}$ and $\mathrm{D}$ indicate that $\mathrm{H}_{2} \mathrm{O}$ is approaching full equilibrium) due to continued formation from late burning $\mathrm{CH}_{4}$ and from consumption due to water shift reactions and oxidation of CO. The "flatness" of the $X_{\mathrm{H} 2 \mathrm{O}}$ and $X_{\mathrm{O} 2}$ RMS profiles is probably due to recirculation/turbulent transport and the slow reaction of $\mathrm{CH}_{4}$. The "flatness" of the temperature RMS profile can be explained with similar arguments. Considering that heat release primarily occurs as a result of $\mathrm{H}_{2} \mathrm{O}$ and $\mathrm{CO}_{2}$ formation, this flatness of the $X_{i}$ profiles could be because product formation is spread out across the cavity. This may also be a consequence of the fast reaction of $\mathrm{H}_{2}$ and relatively slow reaction of $\mathrm{CH}_{4}$. While this was an expected result, the use of only temperature and/or PLIF measurements would not be sufficient to prove this point. Additionally, a similar result might be expected even for a cracked jet-fuel, since ethylene $\left(\mathrm{C}_{2} \mathrm{H}_{4}\right)$ would react much faster than the other components, again producing "staged" combustion. In any event, this study provides a benchmark database with a relatively simple chemistry (as compared to higher order hydrocarbons or jet fuel) in a complex geometry and flow field, which we believe will be useful for validation of advanced computational tools.

\section{Conclusion}

UV spontaneous Raman scattering measurements of temperature and major species concentrations $\left(\mathrm{H}_{2}, \mathrm{CH}_{4}, \mathrm{CO}_{2}, \mathrm{CO}, \mathrm{O}_{2}\right.$, and $\left.\mathrm{N}_{2}\right)$ were recorded over a ramp close-out cavity in the Mach-2 scramjet test section of Research Cell 19 at Wright-Patterson Air Force Base. These measurements - the first of their kind - were made in spite of various challenges including low gas density, the presence of windows (near the probe region), and fluorescence interferences typical of practical combustors and fuels. While the presence of broadband fluorescence interference exacerbated the signal quality and increased measurement uncertainty, the data were of sufficient quality that significant conclusions could be made regarding combustion within the pilot of a scramjet combustor.

The cavity flow field was directly fueled from the ramp using a fuel composed of $70 \% \mathrm{CH}_{4}$ and $30 \% \mathrm{H}_{2}$ (by volume). Results showed that $\mathrm{H}_{2}$ fuel quickly reacted while the $\mathrm{CH}_{4}$ fuel reacted slowly. Indeed, $\mathrm{CH}_{4}$ was largely unreacted by the time it reached the leading edge of the cavity, forming a fuel-rich region along the floor and behind the step at high temperature (due to 
the fast reaction of $\mathrm{H}_{2}$ ). This region of hot, unreacted $\mathrm{CH}_{4}$ may have resulted in production of polycyclic aromatic hydrocarbons (PAH), thus creating the broadband interference observed in this region.

Measurements of mixture faction indicated that the cavity was rich overall; however turbulent transport of $\mathrm{O}_{2}$ across the shear layer eventually resulted in lean mixtures over the ramp. The path of the injected fuel was traced out through the cavity using scatter plots, and $\mathrm{CH}_{4}$ was mainly unreacted near the injectors and behind the step, partially reacted by the midpoint of the cavity below the shear layer, and reacted near the ramp where the products will either exit the cavity or recirculate. Comparisons between $\mathrm{CO}$ and $\mathrm{CO}_{2}$ concentration profiles showed that $\mathrm{CO}$ began to oxidize after the $\mathrm{CH}_{4}$ concentrations decreased near the midpoint of the cavity below the shear layer and that $\mathrm{CO}$ was nearly gone by the ramp, although there was still scatter in the $\mathrm{CO}_{2}$ concentration. While the $\mathrm{H}_{2}$ fuel quickly reacted near the ramp injectors, $\mathrm{H}_{2}$ concentrations were observed where $\mathrm{CO}$ began to oxidize, probably due to the water shift reaction. Data taken in the shear layer demonstrated turbulent transport across the shear layer of $\mathrm{O}_{2}$ into the cavity and hot products into the main flow of tunnel. Fluctuations in measured temperature and $\mathrm{O}_{2}$, and $\mathrm{H}_{2} \mathrm{O}$ concentration were fairly constant throughout the cavity, primarily due to the slow reaction of $\mathrm{CH}_{4}$ and to a combination of recirculation of hot products and turbulent transport of $\mathrm{O}_{2}$ across the shear layer.

Even though the $\mathrm{H}_{2}$ fuel component quickly reacted, providing the high temperature and radicals to sustain the reaction, the slow reaction of $\mathrm{CH}_{4}$ delayed the formation of both $\mathrm{CO}$ and $\mathrm{CO}_{2}$. Additionally, these results show the importance of measuring all major species when multi-component fuels are used, in order to properly determine the combustion behavior and progress, even in the relatively simple fuel mixture used in the current experiment. Finally, this study provides a benchmark database with a relatively simple chemistry in a complex geometry and flow field that can be used for validation of advanced computational models and simulations.

Acknowledgments This research was supported by the Air Force Office of Scientific Research, Combustion and Diagnostics Program (Julian Tishkoff, Manager under contract No. FA9550-091-0205). N. R. Grady was supported by an AFOSR Summer Faculty Fellowship. The authors also thank technicians, D. Schommer and W. Terry, at Wright-Patterson AFB and Vanderbilt student Jennifer Frankland for their assistance.

[1] Pitsch, H., Desjardins, O., Balarac, G., and Ihme, M., 2008, "Large-eddy simulation of turbulent reacting flows," Prog. Aerosp. Sci., 44(6), pp. 466-478.

[2] Sheikhi, M. R. H., Drozda, T. G., Givi, P., Jaberi, F. A., and Pope, S. B., 2005, "Large eddy simulation of a turbulent nonpremixed piloted methane jet flame (Sandia Flame D)," Proc. Combust. Inst., 30, pp. 549-556.

[3] Genin, F., and Menon, S., 2010, "Simulation of turbulent mixing behind a strut injector in supersonic flow," AIAA J., 48(3), pp. 526-539.

[4] Grady, N. R., Pitz, R. W., Carter, C. D., Hsu, K.-Y., Ghodke, C., and Menon, S., 2011, "Supersonic flow over a ramped-wall cavity flameholder with an upstream strut," J. Propul. Power, 28(5), pp. 982-990.

[5] Gicquel, L. Y. M., Staffelbach, G., and Poinsot, T., 2012, "Large Eddy Simulations of gaseous flames in gas turbine combustion chambers," Prog. Energy and Combust. Sci., 38(6), pp. 782-817. 
[6] O'Byrne, S., Danehy, P. M., Tedder, S. A., and Cutler, A. D., 2007, "Dual-pump coherent anti-Stokes Raman scattering measurements in a supersonic combustor," AIAA J., 45(4), pp. 922-933.

[7] Hancock, R. D., Schauer, F. R., Lucht, R. P., and Farrow, R. L., 1997, "Dual-pump coherent anti-Stokes Raman scattering measurements of nitrogen and oxygen in a laminar jet diffusion flame," Appl. Optics, 36(15), pp. 3217-3226.

[8] Lucht, R. P., Velur-Natarajan, V., Carter, C. D., Grinstead, K. D., Gord, J. R., Danehy, P. M., Fiechtner, G. J., and Farrow, R. L., 2003, "Dual-pump coherent anti-Stokes Raman scattering temperature and $\mathrm{CO}_{2}$ concentration measurements," AIAA J., 41(4), pp. 679-686.

[9] Magnotti, G., Cutler, A. D., and Danehy, P. M., 2013, "Development of a dual-pump coherent anti-Stokes Raman spectroscopy system for measurements in supersonic combustion," Appl. Optics, 52(20), pp. 4779-4791.

[10] Fulton, J. A., Edwards, J. R., Hassan, H. A., McDaniel, J. C., Goyne, C. P., Rockwell, R. D., Cutler, A. D., Johansen, C. T., and Danehy, P. M., 2014, "Large-Eddy/Reynolds-Averaged Navier-Stokes Simulations of Reactive Flow in Dual-Mode Scramjet Combustor," J. Propul. Power, 30(3), pp. 558-575.

[11] Tedder, S. A., Wheeler, J. L., Cutler, A. D., and Danehy, P. M., 2010, "Width-increased dual-pump enhanced coherent anti-Stokes Raman spectroscopy," Appl. Optics, 49(8).

[12] Roy, S., Gord, J. R., and Patnaik, A. K., 2010, "Recent advances in coherent anti-Stokes Raman scattering spectroscopy: Fundamental developments and applications in reacting flows," Prog. Energy and Combust. Sci., 36(2).

[13] Kohse-Höinghaus, K., 2002, Applied Combustion Diagnostics, CRC Press, New York, N.Y. [14] Kutne, P., Kapadia, B. K., Meier, W., and Aigner, M., 2011, "Experimental analysis of the combustion behaviour of oxyfuel flames in a gas turbine model combustor," Proc. Combust. Inst., 33, pp. 3383-3390.

[15] Meier, W., Boxx, I., Stohr, M., and Carter, C. D., 2010, "Laser-based investigations in gas turbine model combustors," Exp. in Fluids, 49(4), pp. 865-882.

[16] Stopper, U., Aigner, M., Ax, H., Meier, W., Sadanandan, R., Stohr, M., and Bonaldo, A., 2010, "PIV, 2D-LIF and 1D-Raman measurements of flow field, composition and temperature in premixed gas turbine flames," Exp. Therm. Fluid Sci., 34(3), pp. 396-403.

[17] Cheng, T. S., Wehrmeyer, J. A., Pitz, R. W., Jarrett, O., and Northam, G. B., 1994, "Raman measurement of mixing and finite-rate chemistry in a supersonic hydrogen-air diffusion flame," Combust. Flame, 99(1), pp. 157-173.

[18] Lin, K. C., Ryan, M., Carter, C., Gruber, M., and Raffoul, C., 2010, "Raman Scattering Measurements of Gaseous Ethylene Jets in Mach 2 Supersonic Crossflow," J. Propul. Power, 26(3), pp. 503-513.

[19] Gruber, M. R., Carter, C. D., Montes, D. R., Haubelt, L. C., Kings, P. I., and Hsu, K. Y., 2008, "Experimental studies of pylon-aided fuel injection into a supersonic crossflow," J. Propul. Power, 24(3), pp. 460-470.

[20] Ben-Yakar, A., and Hanson, R. K., 2001, "Cavity flame-holders for ignition and flame stabilization in scramjets: An overview," J. Propul. Power, 17, pp. 869-877.

[21] Gruber, M. R., Donbar, J. M., Carter, C. D., and Hsu, K. Y., 2004, "Mixing and combustion studies using cavity-based flameholders in a supersonic flow," J. Propul. Power, 20(5), pp. 769778. 
[22] Rasmussen, C. C., Driscoll, J. F., Hsu, K. Y., Donbar, J. M., Gruber, M. R., and Carter, C. D., 2005, "Stability limits of cavity-stabilized flames in supersonic flow," Proc. Combust. Inst., 30, pp. 2825-2833.

[23] Do, H., Carter, C. D., Liu, Q., Ombrello, T. M., Hammack, S., Lee, T., and Hsu, K.-Y., 2015, "Simultaneous gas density and fuel concentration measurements in a supersonic combustor using laser induced breakdown," Proc. Combust. Inst., 35, pp. 2155-2162.

[24] Tuttle, S. G., Carter, C. D., and Hsu, K.-Y., 2014, "Particle Image Velocimetry in a Nonreacting and Reacting High-Speed Cavity," J. Propul. Power, 30(3), pp. 576-591. [25] Ombrello, T. M., Carter, C. D., Tam, C.-J., and Hsu, K.-Y., 2015, "Cavity ignition in supersonic flow by spark discharge and pulse detonation," Proc. Combust. Inst., 35, pp. 21012108.

[26] Wehr, L., Meier, W., Kutne, P., and Hassa, C., 2007, "Single-pulse ID laser Raman scattering applied in a gas turbine model combustor at elevated pressure," Proc. Combust. Inst., 31, pp. 3099-3106.

[27] Cheng, T. S., 1991, "Laser Raman diagnostics in subsonic and supersonic turbulent jet diffusion flames," Ph.D., Vanderbilt University.

[28] Nandula, S. P., 1995, "Measurements of mixing scalars and scalar dissipation in turbulent flames by line Raman imaging," M.S., Vanderbilt University.

[29] Mansour, M. S., and Chen, Y. C., 1996, "Line Raman, Rayleigh, and laser-induced

predissociation fluorescence technique for combustion with a tunable KrF excimer laser," Appl. Optics, 35(21), pp. 4252-4260.

[30] Pitsch, H., and Peters, N., 1998, "A consistent flamelet formulation for non-premixed combustion considering differential diffusion effects," Combust. Flame, 114(1-2), pp. 26-40. [31] Hsu, K. Y., Carter, C. D., Gruber, M. R., Barhorst, T., and Smith, S., 2010, "Experimental study of cavity-strut combustion in supersonic flow," J. Propul. Power, 26(6), pp. 1237-1246. 


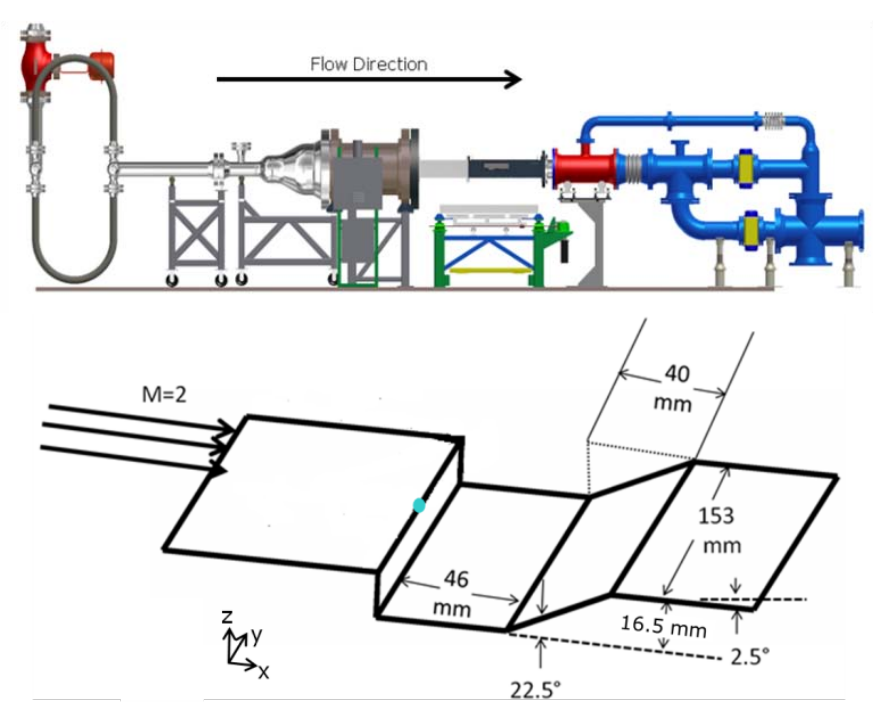

Figure 1: Research Cell 19 wind tunnel schematic (top), and close-up of combustor and cavity (bottom) with the blue dot located on the leading edge of the cavity and the centerline of the combustor $(x=0, y=0, z=0)$

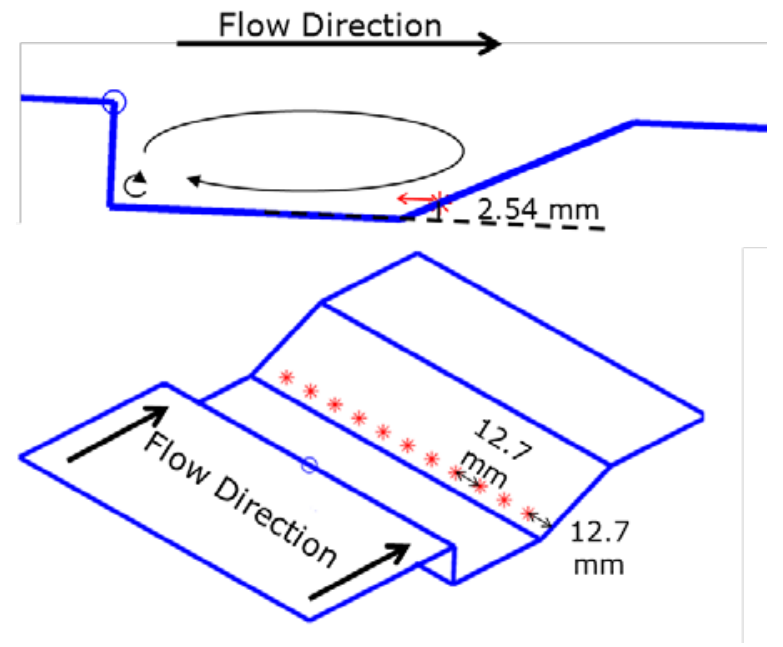

Figure 2: Close-up of the fuel (red stars) injectors from the side (top) and from above at an angle (bottom). The 11 fuel injectors are spaced $12.7 \mathrm{~mm}$ apart with an exit diameter of $1.98 \mathrm{~mm}$ supplying a $70 \% \mathrm{CH}_{4} / 30 \% \mathrm{H}_{2}$ fuel blend. The recirculation zones and flow patterns are indicated in the top figure. 

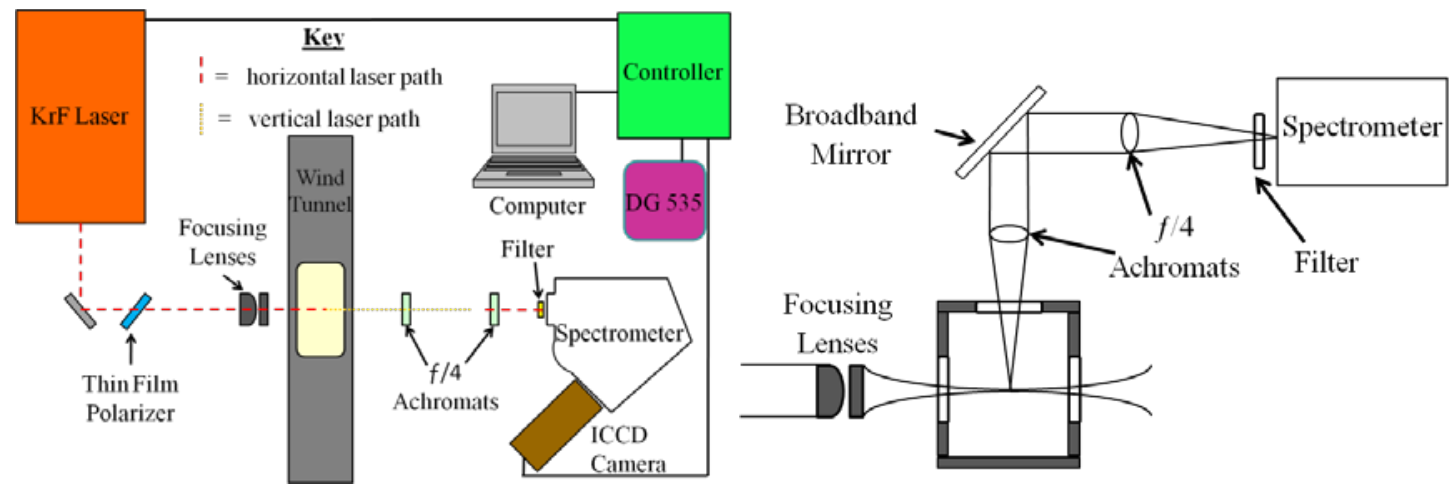

Figure 3: Schematic of the UV Raman experimental system (left) with side view of collection system (right).

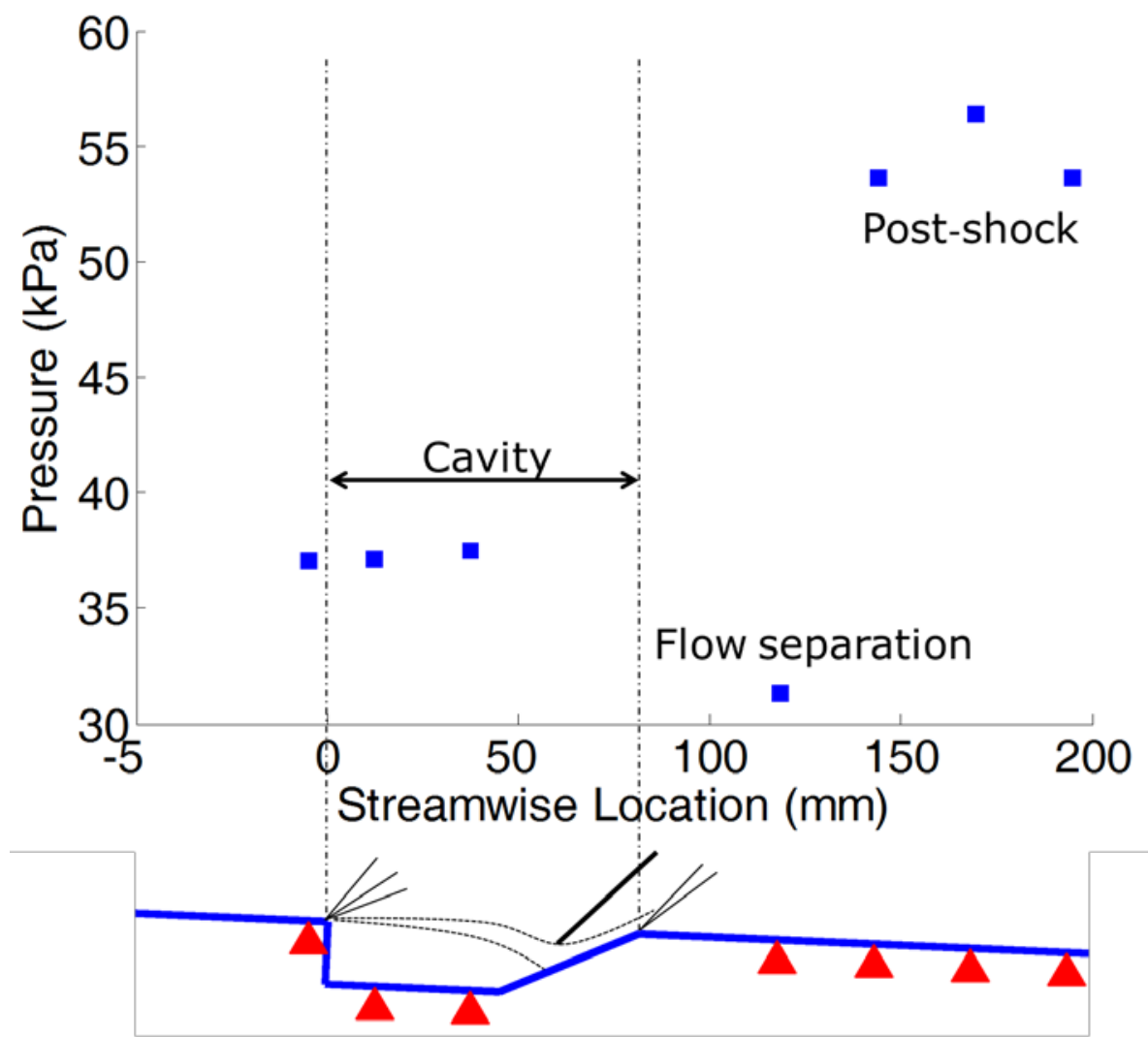

Figure 4: Sample mean wall pressures and the standard deviation of the 1-Hz measurement was generally $<1 \%$. Insert shows the pressure port locations (solid triangles) with respect to the cavity. Flow pattern sketched following Figure 5b in [20]. 

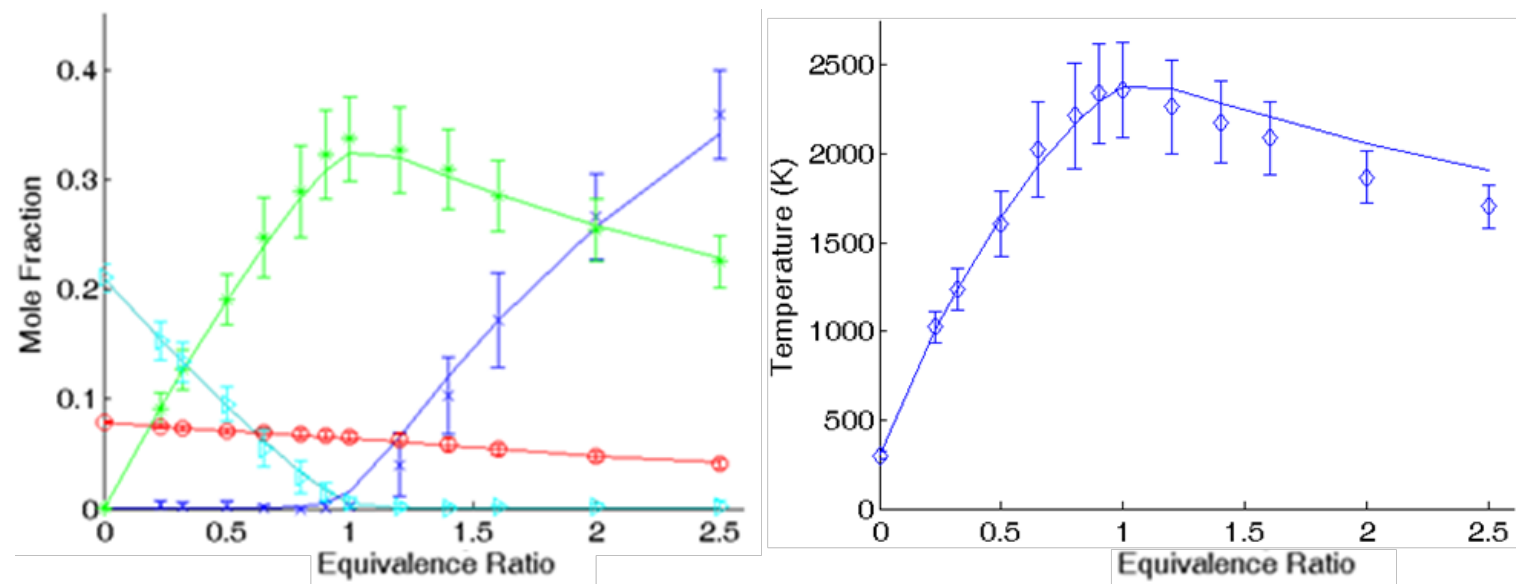

Figure 5: Calibration plots of Raman data over a Hencken burner using an $\mathrm{H}_{2}$-air flame at ambient (laboratory) pressure. The points are the mean values and the bars represent one standard deviation. Solid lines represent adiabatic equilibrium values.
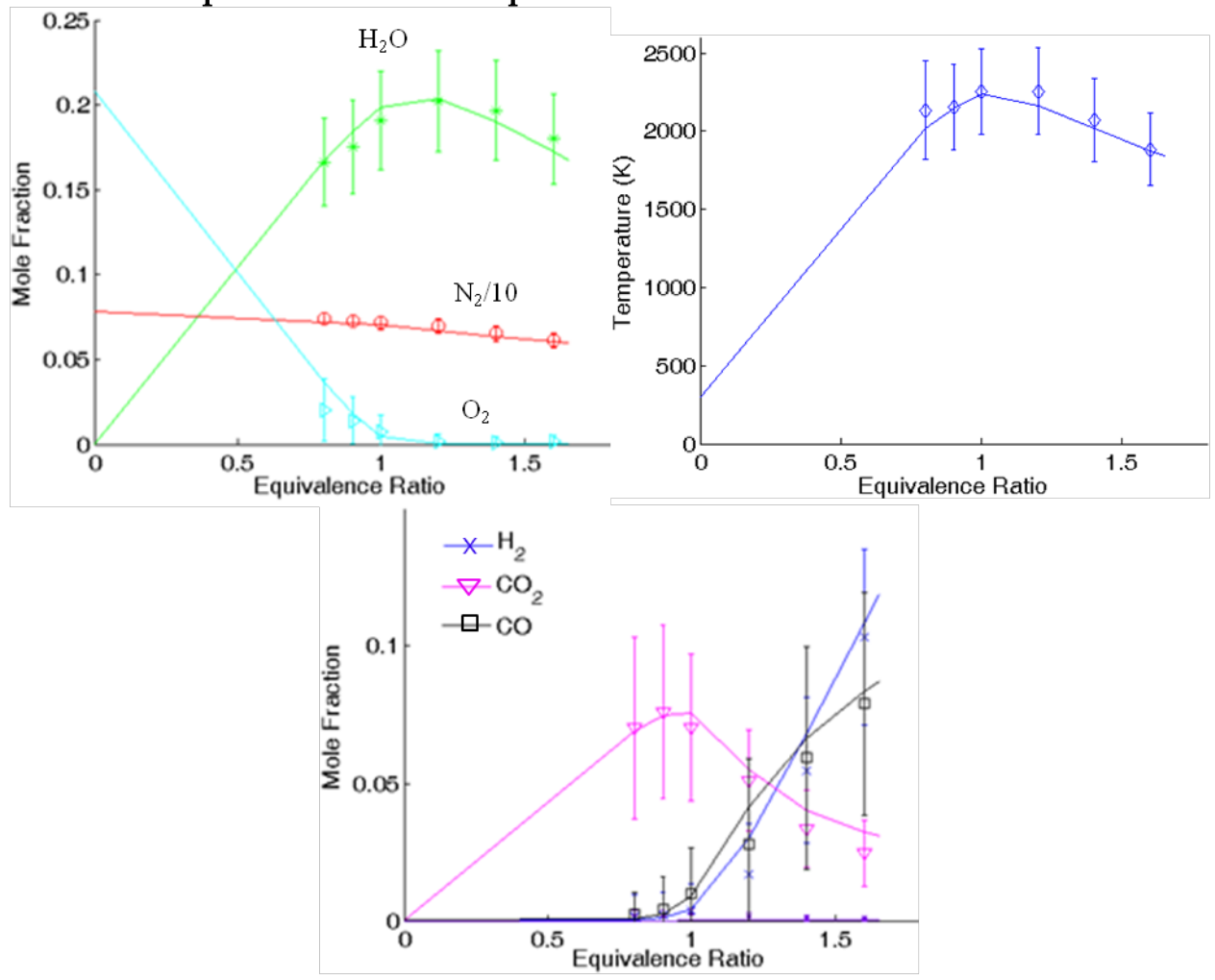

Figure 6: Calibration plots of Raman data over a Hencken burner using a $70 \% \mathrm{CH}_{4} / 30 \% \mathrm{H}_{2}$-air flame at ambient (laboratory) pressure. The points are the mean values and the bars represent one standard deviation from the mean. Solid lines represent adiabatic equilibrium values. 


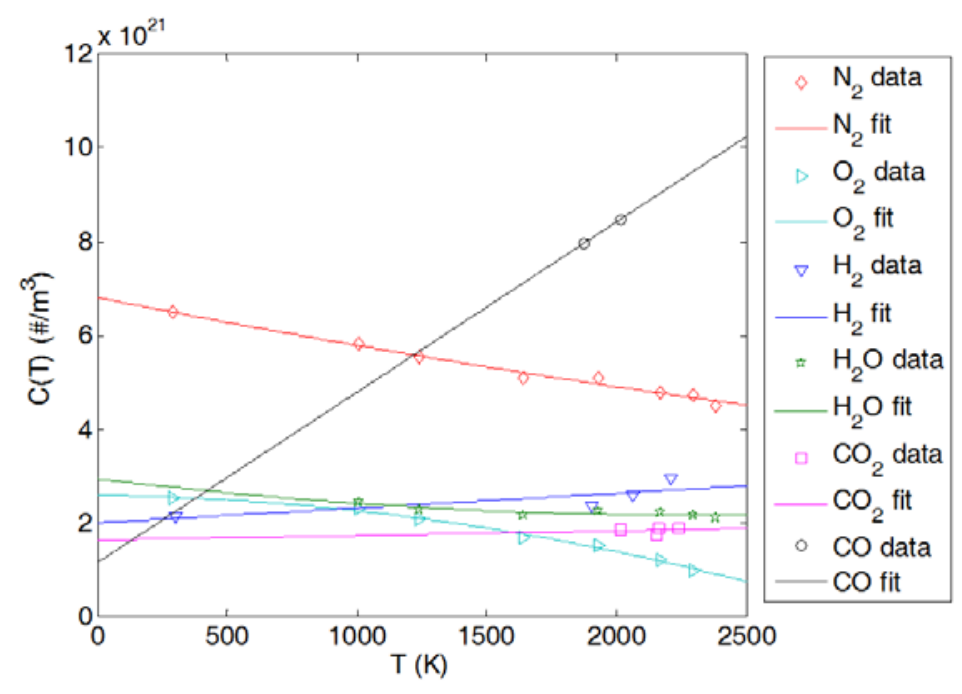

Figure 7: Calibration factors, C(T), vs. temperature obtained from the Hencken burner. The C(T) for $\mathrm{CH}_{4}$ measured at room temperature and assumed to be invariant with temperature.
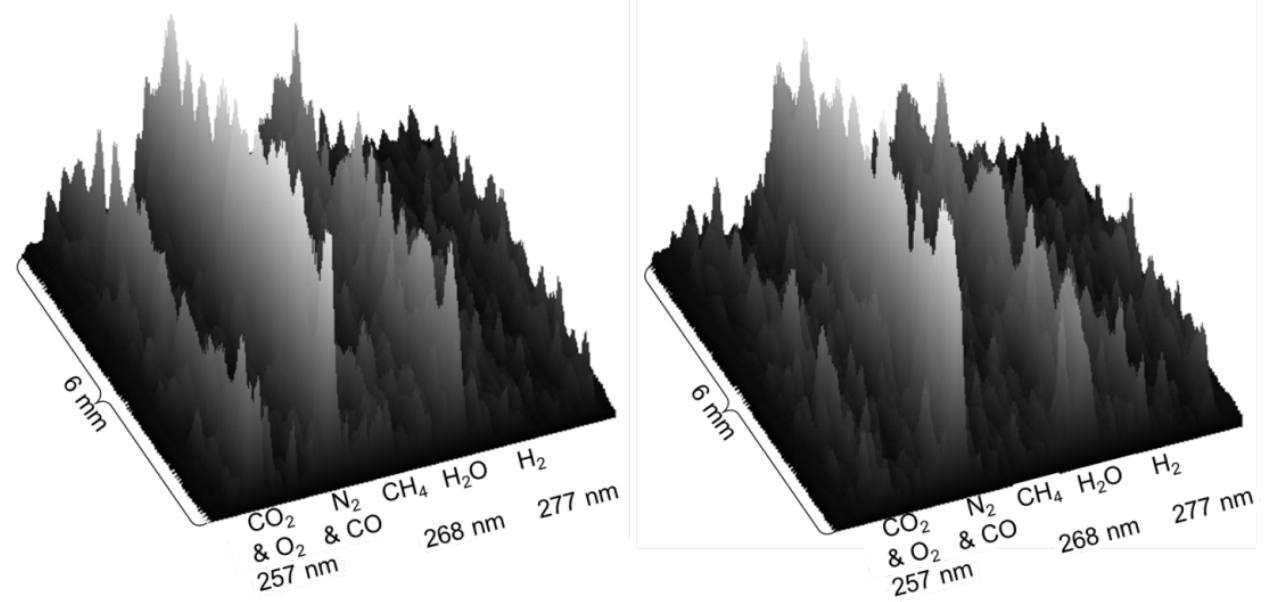

Figure 8: Raw, single-shot line spectral images of calibration data of $70 \% \mathrm{CH}_{4} / 30 \% \mathrm{H}_{2}$ fuel mixture at $\phi=1$ (left) and $\phi=1.6$ (right). 


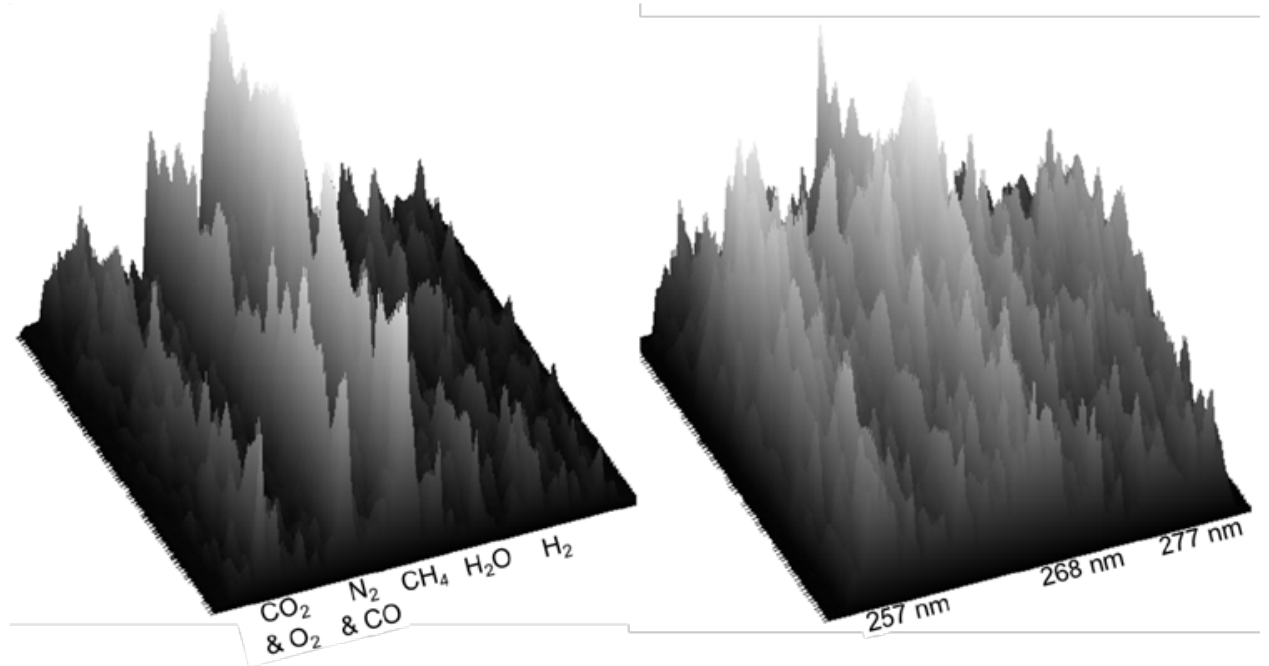

Figure 9: Raman single-shot spectra taken inside the combustor showing a reducible image (left), and an irreducible image (right) due to broadband interference during combustion both taken at $x$ $=0.9 \mathrm{~cm}$ and $\mathrm{y}=0.9 \mathrm{~cm}$ where the wall pressure is $37 \mathrm{kPa}$. The maximum value of the right image is $\sim 20 \%$ more than the maximum of the left image.

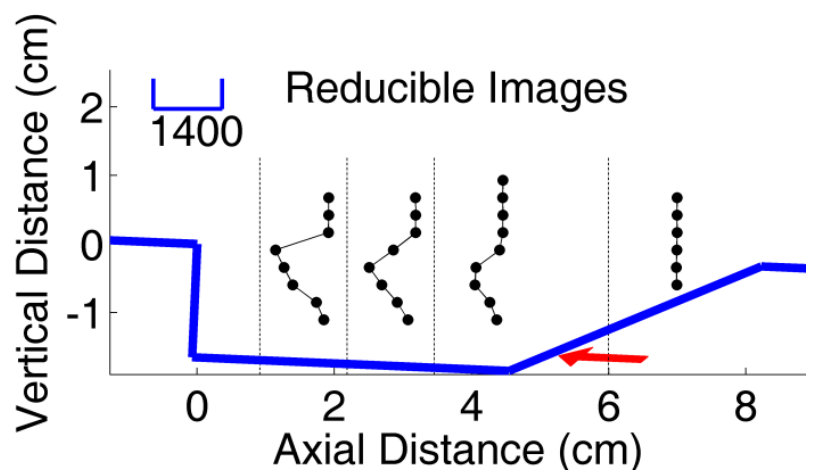

Figure 10: Number of reducible images. The insert in the upper left represent the maximum value of the figure.

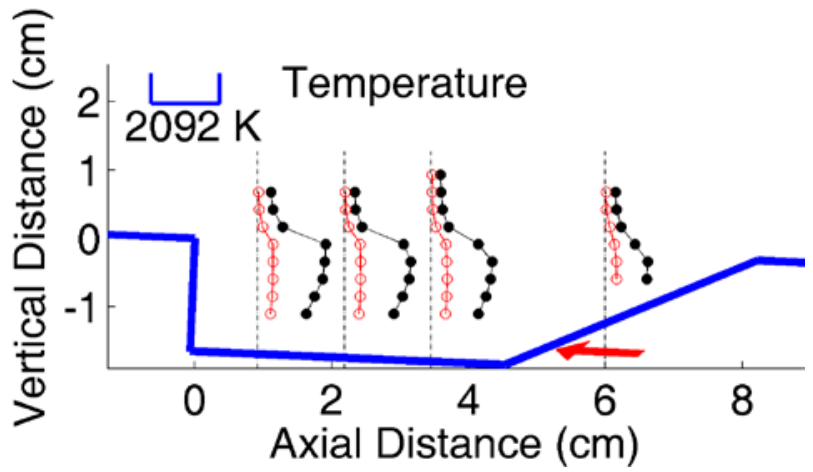

Figure 11: Experimental mean (black) and RMS fluctuation (red) temperature data. The insert in the upper left represent the maximum value of the figure. 


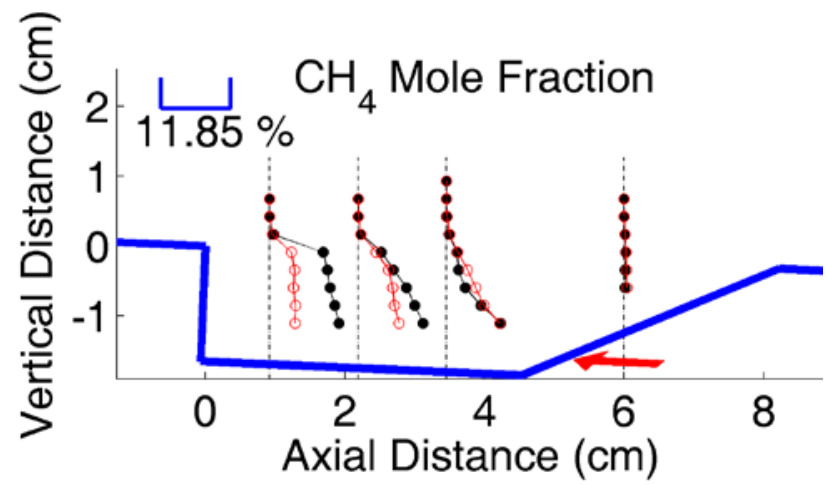

Figure 12: Experimental mean (black) and RMS fluctuation (red) $\mathrm{CH}_{4}$ data. The insert in the upper left represent the maximum value of the figure.

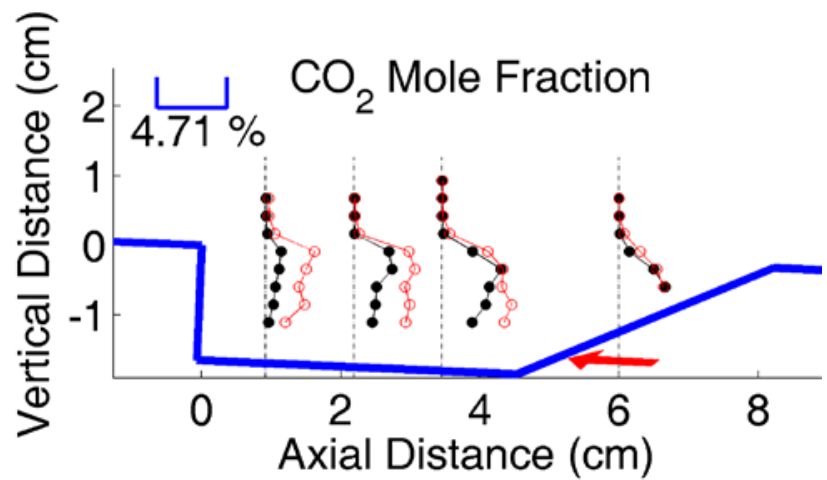

Figure 13: Experimental mean (black) and RMS fluctuation (red) $\mathrm{CO}_{2}$ data. The insert in the upper left represent the maximum value of the figure.

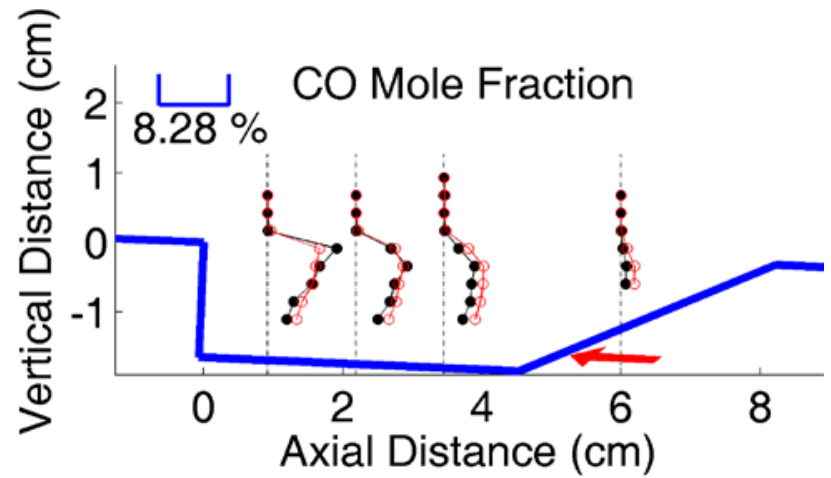

Figure 14: Experimental mean (black) and RMS fluctuation (red) CO data. The insert in the upper left represent the maximum value of the figure. 


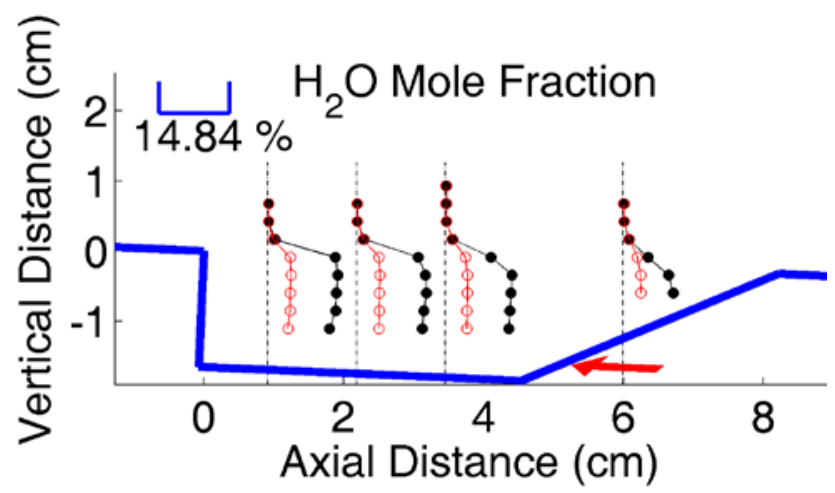

Figure 15: Experimental mean (black) and RMS fluctuation (red) $\mathrm{H}_{2} \mathrm{O}$ data. The insert in the upper left represent the maximum value of the figure.

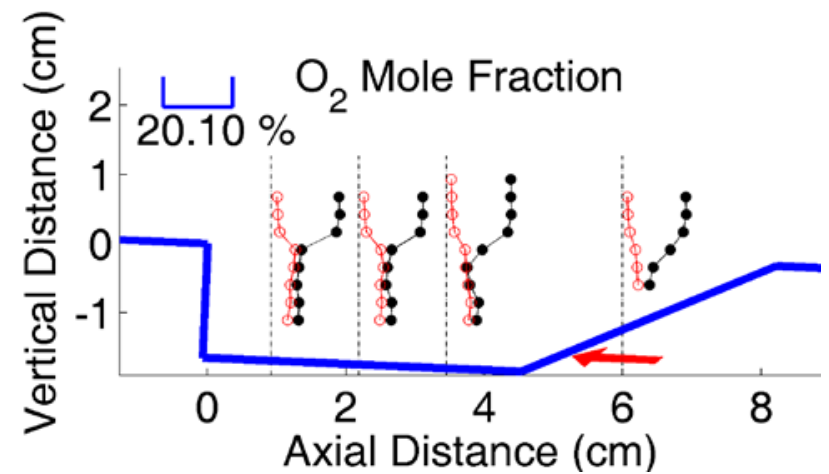

Figure 16: Experimental mean (black) and RMS fluctuation (red) $\mathrm{O}_{2}$ data. The insert in the upper left represent the maximum value of the figure.

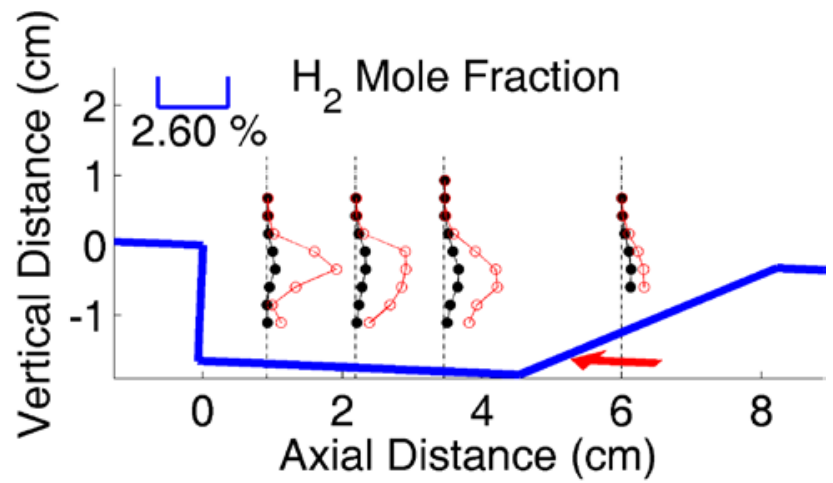

Figure 17: Experimental mean (black) and RMS fluctuation (red) $\mathrm{H}_{2}$ data. The insert in the upper left represent the maximum value of the figure. 


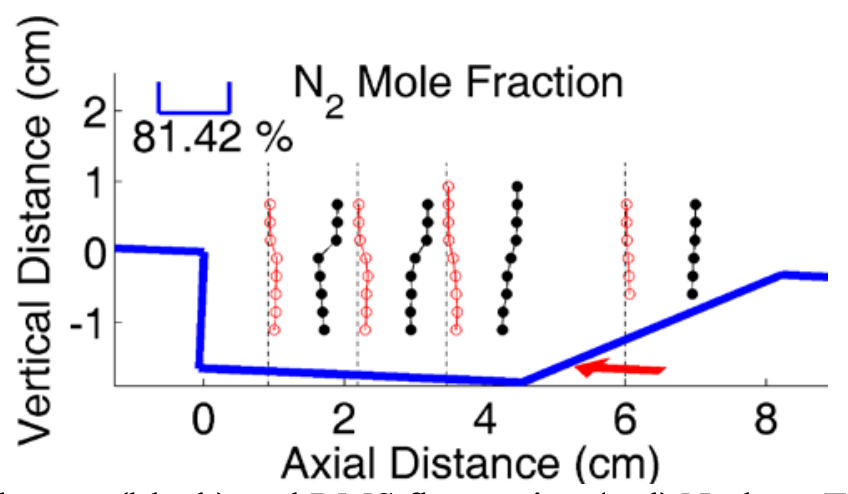

Figure 18: Experimental mean (black) and RMS fluctuation (red) $\mathrm{N}_{2}$ data. The insert in the upper left represent the maximum value of the figure.

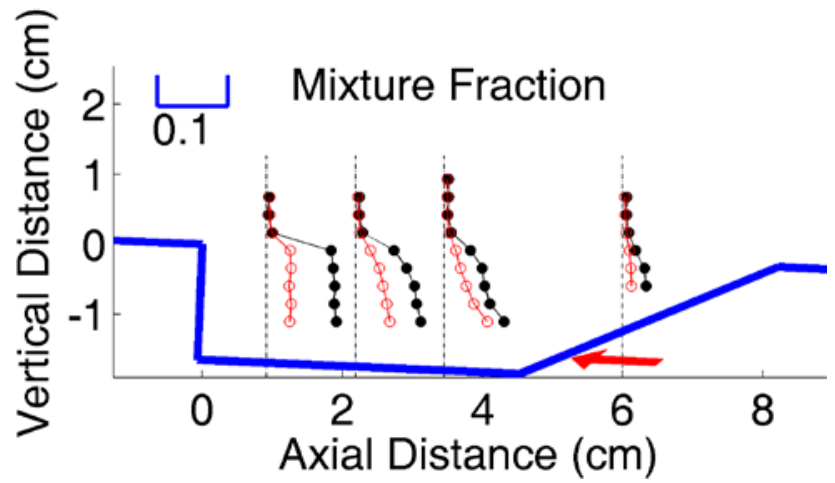

Figure 19: Experimental mean (black) and RMS fluctuation (red) mixture fraction data. The stoichiometric mixture fraction, $\xi_{s t}$, is 0.0525 . The insert in the upper left represent the maximum value of the figure.

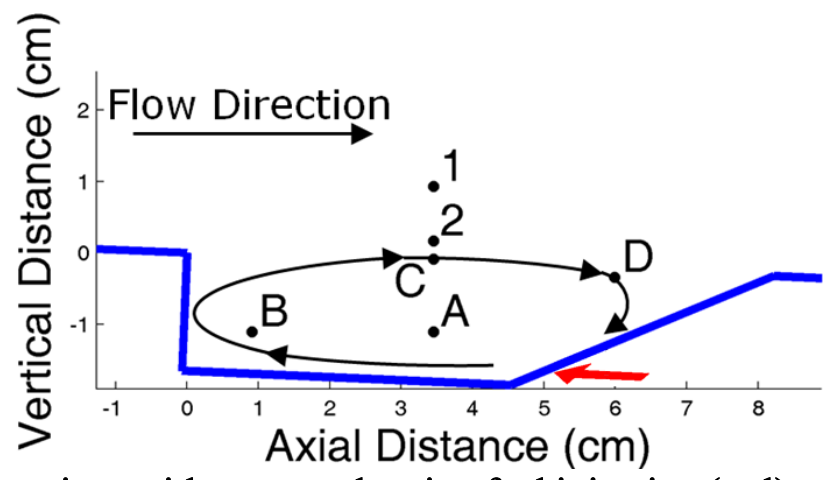

Figure 20: Scatter plot locations with arrows showing fuel injection (red) and the recirculation pattern (black). Location 1 is in the freestream, Location 2 is in the shear layer, and Location $A$ through $\mathrm{D}$ are in the cavity. 

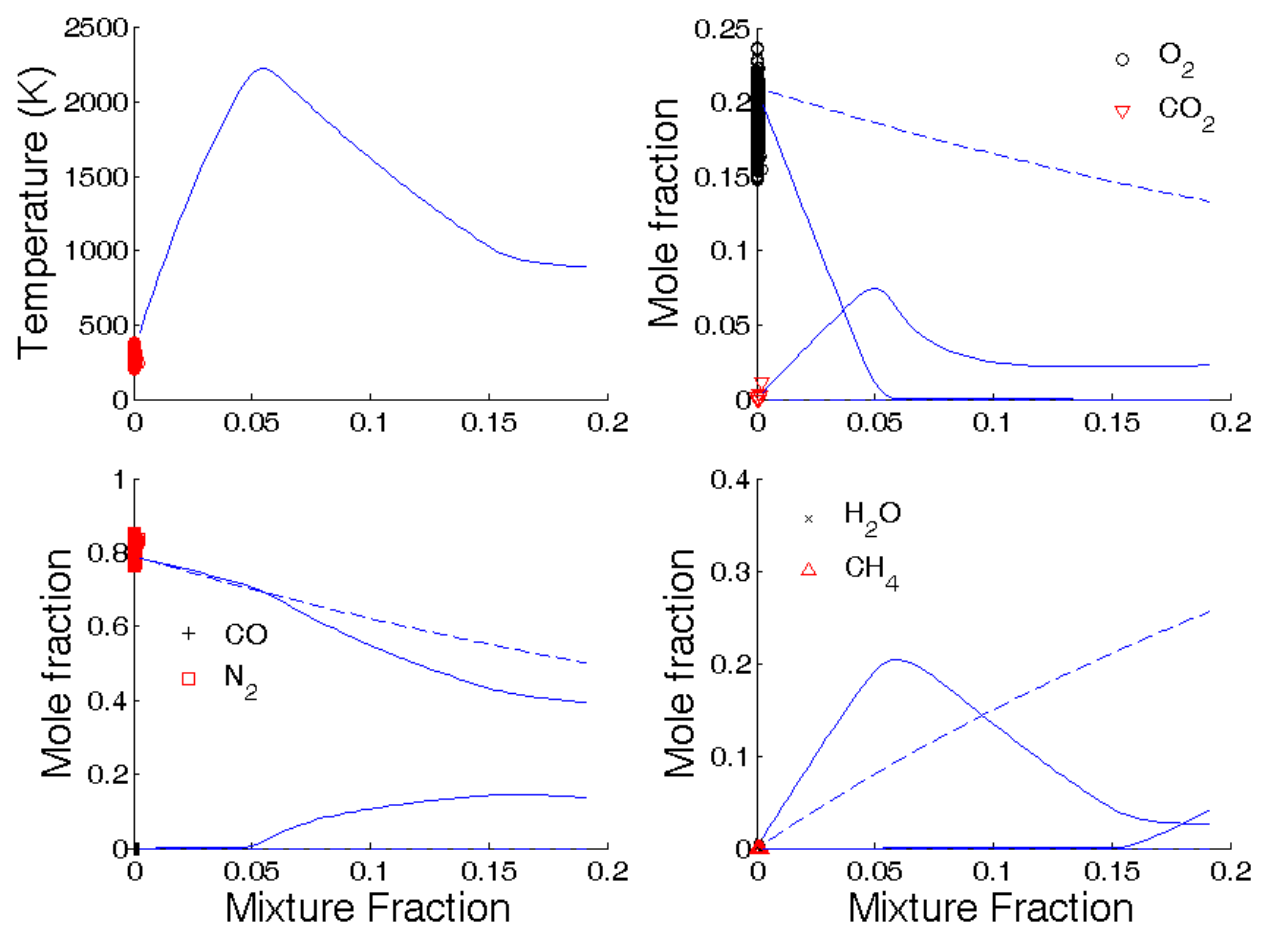

Figure 21: Scatter plots for Location $1(x=3.5 \mathrm{~cm}, y=1 \mathrm{~cm})$ with lines drawn for adiabatic equilibrium (solid) and mixing without reaction (dashed).
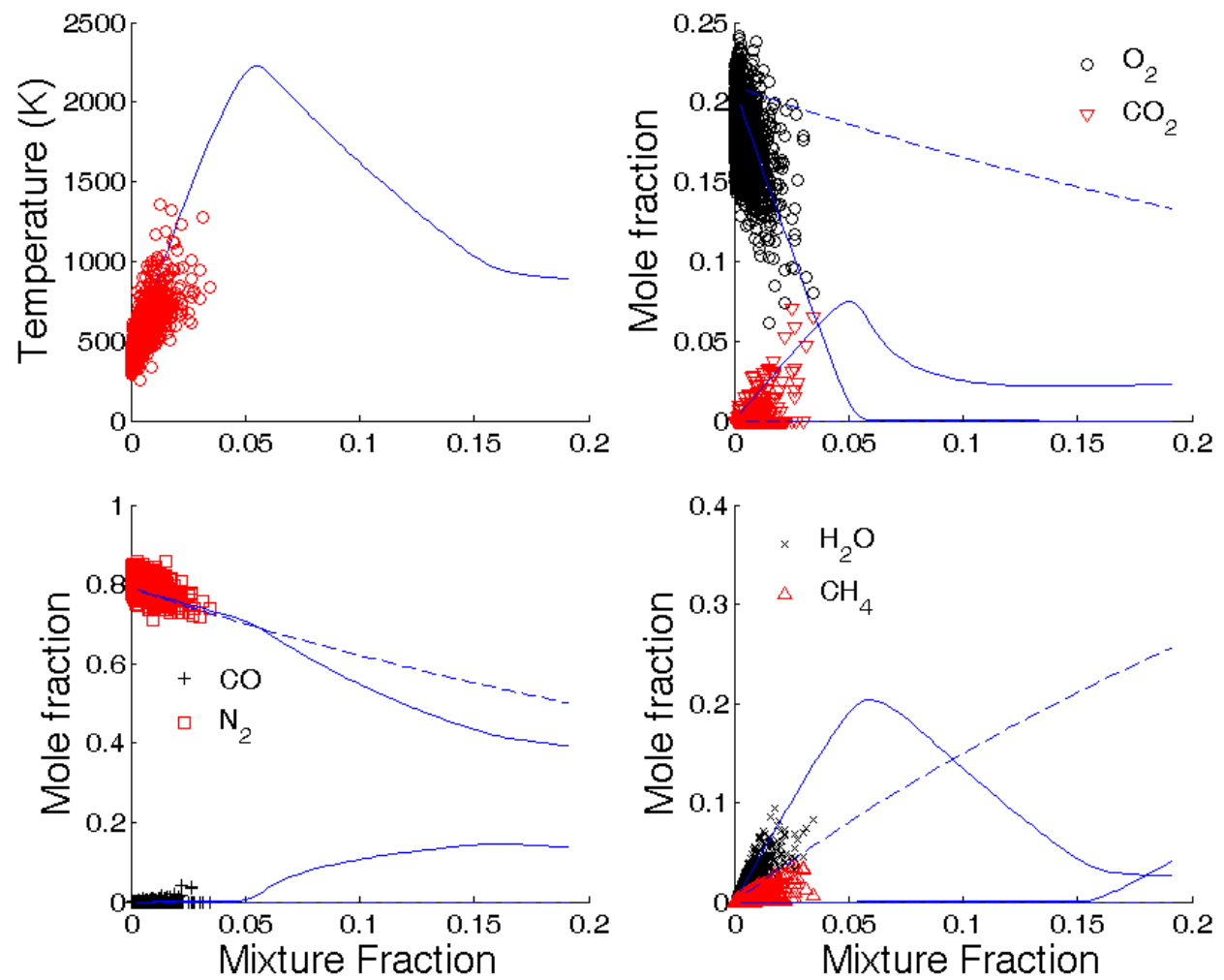

Figure 22: Scatter plots for Location $2(x=3.5 \mathrm{~cm}, y=0.2 \mathrm{~cm})$ with lines drawn for adiabatic equilibrium (solid) and mixing without reaction (dashed). 

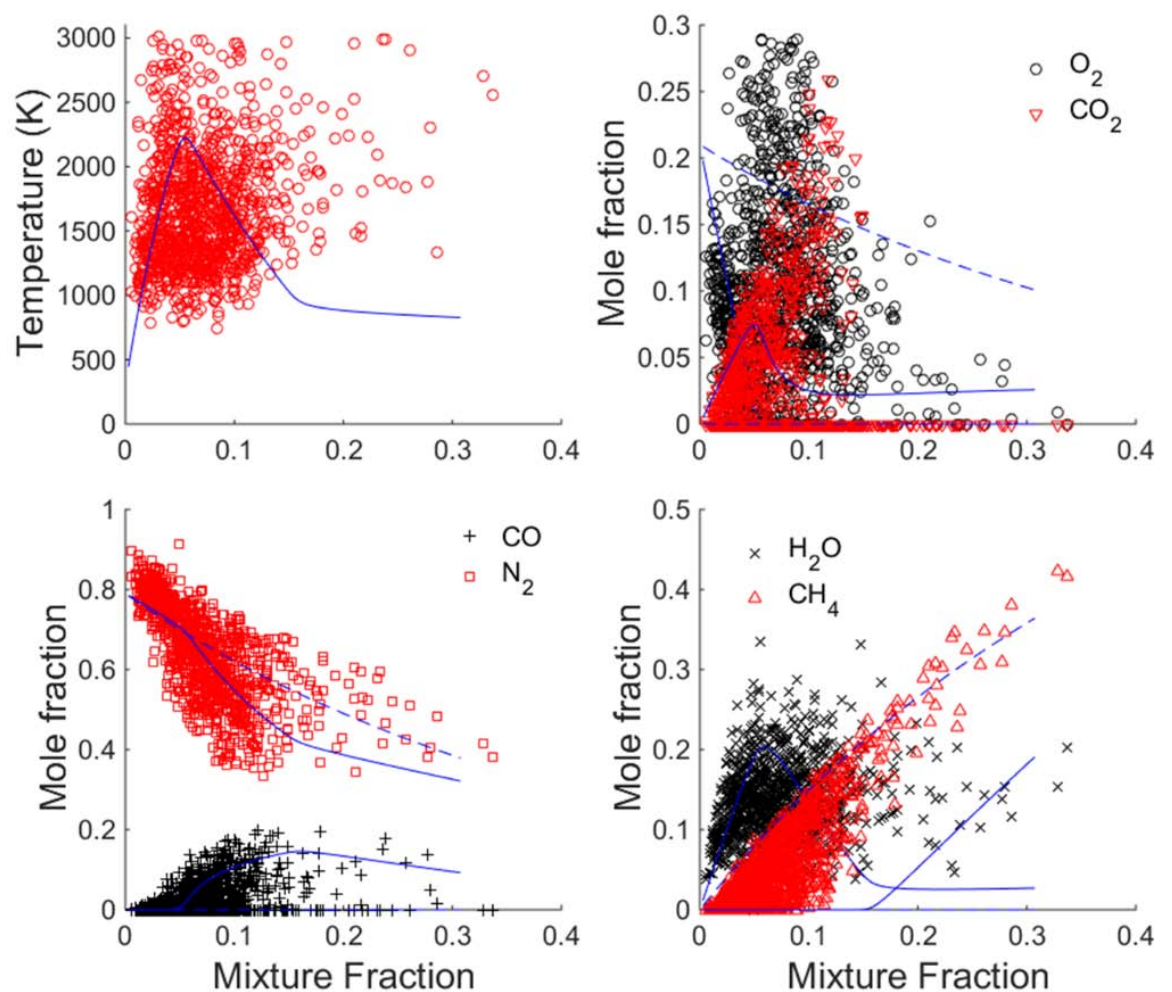

Figure 23: Scatter plots for Location $A(x=3.5 \mathrm{~cm}, y=-1.1 \mathrm{~cm})$ with lines drawn for adiabatic equilibrium (solid) and mixing without reaction (dashed).
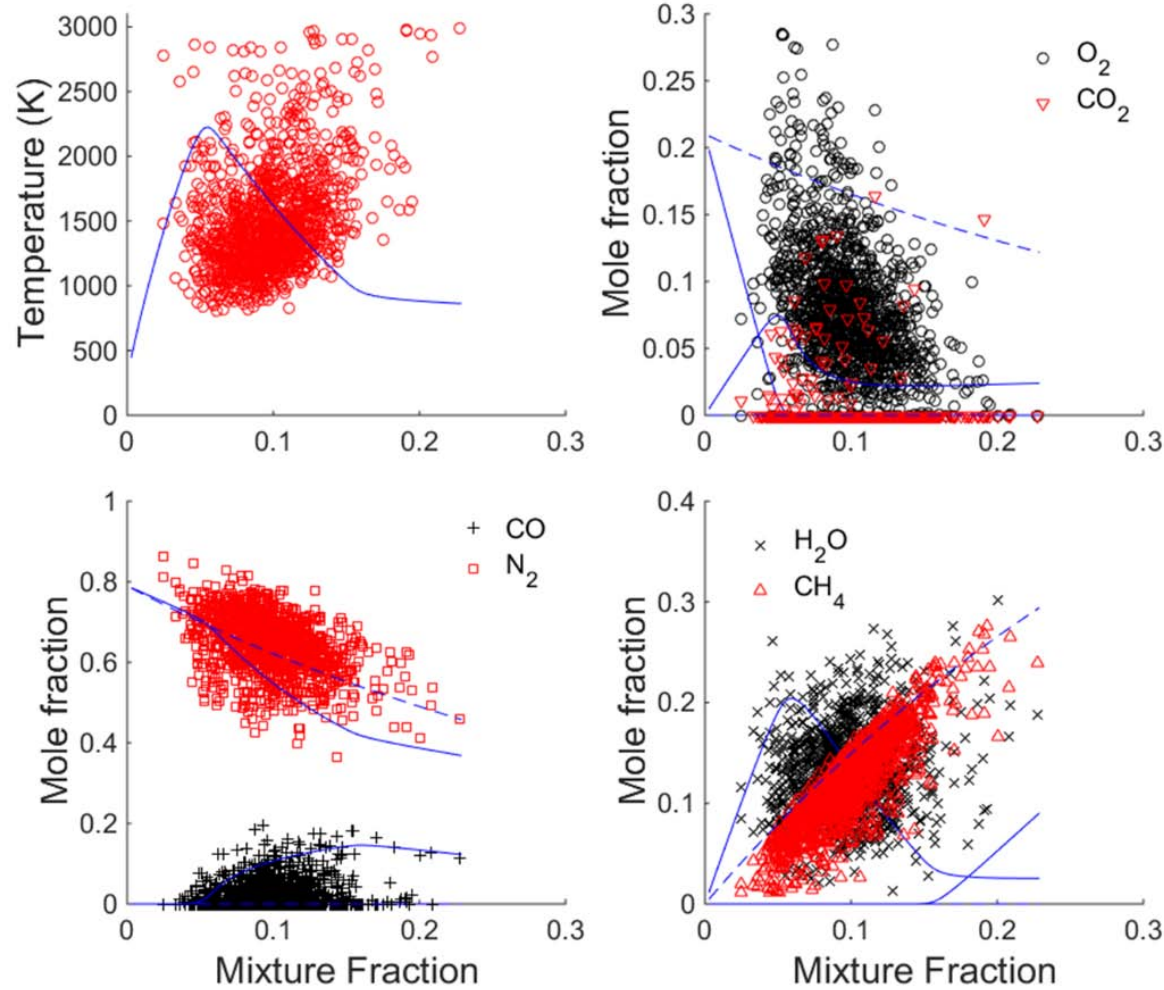

Figure 24: Scatter plots for Location $B(x=0.9 \mathrm{~cm}, y=-1.1 \mathrm{~cm})$ with lines drawn for adiabatic equilibrium (solid) and mixing without reaction (dashed). 

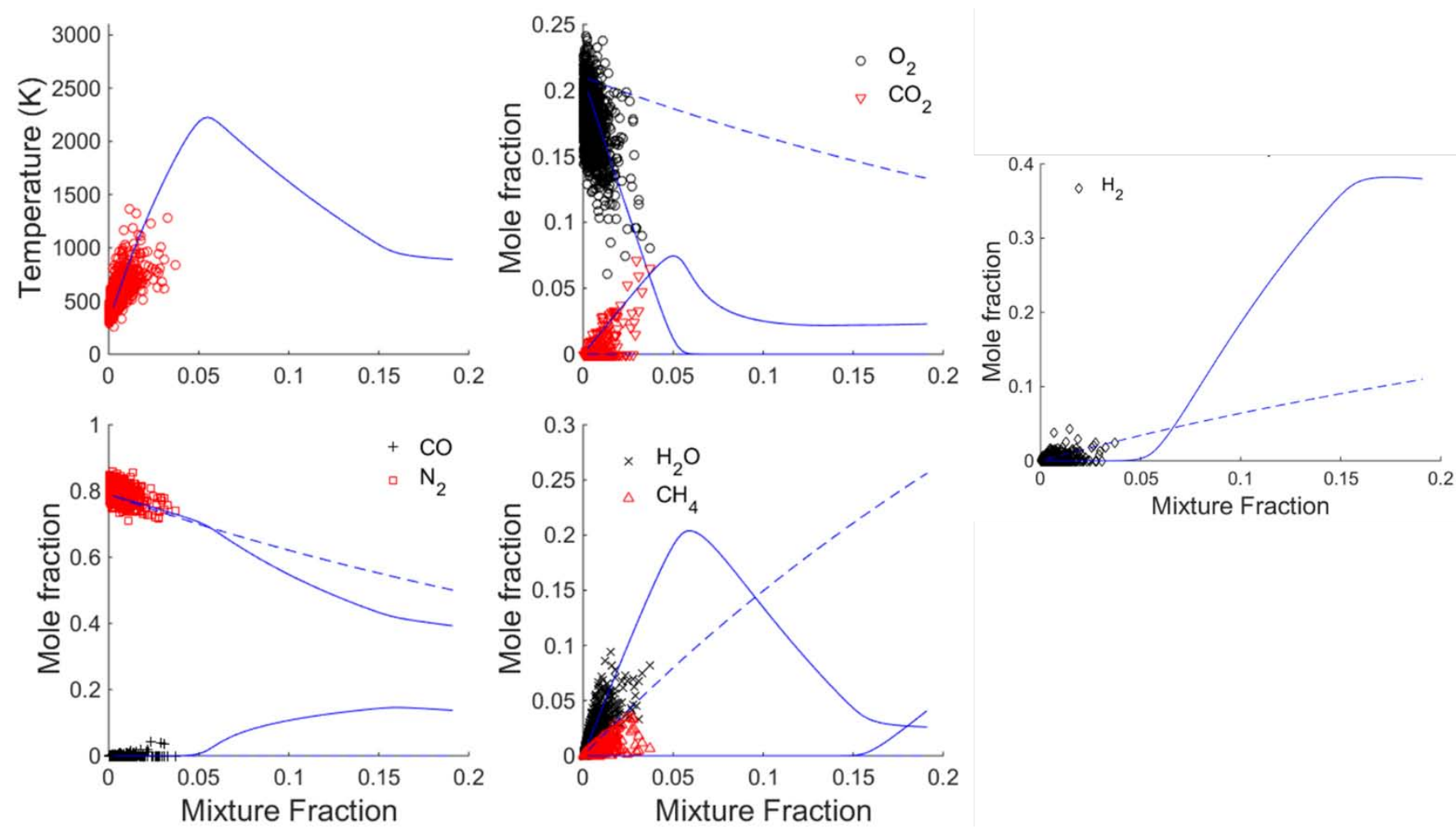

Figure 25: Scatter plots for Location $C(x=3.5 \mathrm{~cm}, y=-0.1 \mathrm{~cm})$ with lines drawn for adiabatic equilibrium (solid) and mixing without reaction (dashed).
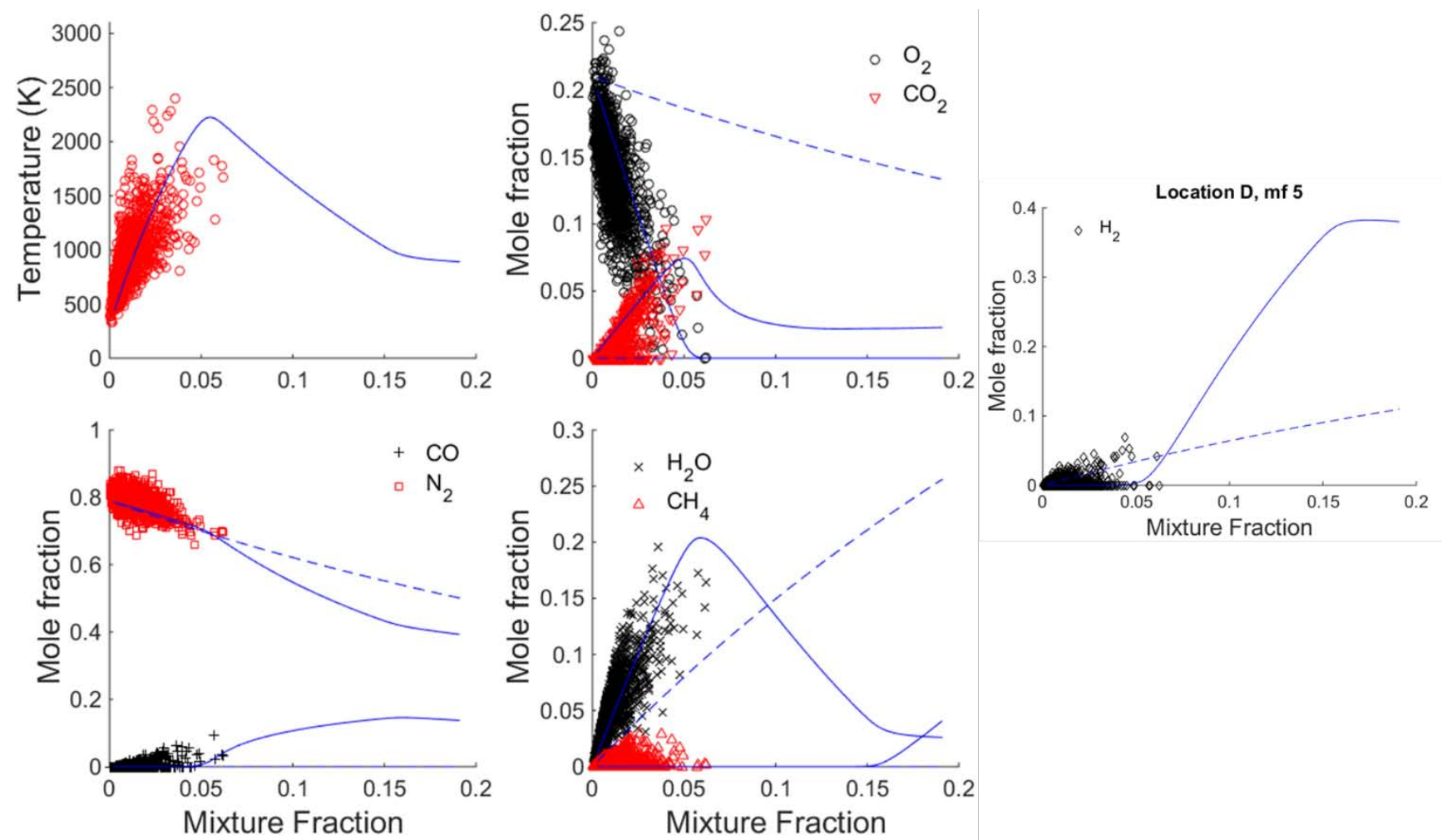

Figure 26: Scatter plots for Location $D(x=6 \mathrm{~cm}, y=-0.3 \mathrm{~cm})$ with lines drawn for adiabatic equilibrium (solid) and mixing without reaction (dashed). 